\title{
The boundaries of interdisciplinary fields: temporalities shaping the past and future of dialogue between migration and mobilities research
}

\author{
Allison Hui \\ a.hui@lancaster.ac.uk
}

\begin{abstract}
This paper contributes to the interdisciplinary fields of migration and mobilities research by temporalizing understandings of their boundaries - places where differences have been entrenched and some concepts have remained beyond negotiation or dialogue. While the creativity and boundary-crossing potential of interdisciplinary fields is often set in opposition to disciplines, which define and regulate appropriate concepts and knowledge, such characterizations obscure how interdisciplinary fields have boundaries that change over and in relation to time. This paper therefore uses three temporal dynamics - a/synchronicity, sequencing, and accumulation over time - to consider the evolving boundaries that have limited collaboration between these fields. By tracing past discussions of concepts such as 'transnationalism', 'mobility' and 'methodological nationalism', it highlights the contingency and complexity of dialogue between these fields, and how they, like disciplines, 'define what it is permissible not to know' (Abbott, 2001, p. 130). The new concept of 'migrant exceptionalism' is introduced to acknowledge the boundaries created through privileging 'migrants' as unique and continuously relevant subjects. Both migration and mobilities scholars are seen to perpetuate migrant exceptionalism, and countering it through the study of sometimes-migrants is identified as a means of modulating existing boundaries and opening new spaces for interdisciplinary dialogue.
\end{abstract}

\section{Keywords}

Mobilities; migration; migrant exceptionalism; temporalities; interdisciplinary; methodological nationalism; transnationalism; Hong Kong

The Version of Record of this manuscript has been published and is available in Mobilities < add DATE OF PUBLICATION > http://www.tandfonline.com/ http://dx.doi.org/10.1080/17450101.2015.1097033. 
Dialogue between interdisciplinary research fields involves the mobilities of many concepts, which traverse disciplinary boundaries, are applied to varied cases, and support new contributions. Flows of ideas between migration and mobilities scholars have, for instance, contributed to understandings of subjectivities, sexuality, and dwelling (Conradson and McKay, 2007; Crang and Zhang, 2012; Mai and King, 2009), the intersecting movement of humans and objects (Basu and Coleman, 2008; Burrell, 2008, 2011), negotiating multiple returns home (Ahmed et al., 2003; King and Christou, 2011), and power dynamics playing out over and through borders (Fortier and Lewis, 2006; Gill et al., 2011; Richardson, 2013). Yet accounts of these flows have often been directed more towards supporting and justifying new knowledge than acknowledging the boundaries, complexity and contingency of interdisciplinary exchange. As Barry et al. note, 'any analysis of the inventiveness of particular kinds of interdisciplinarity must attend to the specificity of interdisciplinary fields, their genealogies and multiplicity' (2008, p. 42). This paper therefore looks at the movement of ignored or contested ideas between the 'inherently interdisciplinary' fields of mobilities research and migration studies (Castles, 2007; Favell, 2001, p. 397; Hannam et al., 2006), in order to extend understandings of their interrelated genealogies (Adey et al., 2014; Fortier, 2014).

In particular, it contributes to discussions of the interdisciplinary fields of migration and mobilities research by temporalizing understandings of their boundaries - places where differences have been entrenched and some concepts have remained beyond negotiation and dialogue. A considerable amount of research has already considered interdisciplinary exchanges, including the structures and characteristics that support successful careers and collaborations (Boix Mansilla et al., 2002; Lyall et al., 2011; National Academies (U.S.) et al., 2005), what leads interdisciplinary experiments to fail (Holland, 2014; Strober, 2010), distinctions between types of interdisciplinary engagements (Barry et al., 2008), and how dialogue can reveal and challenge disciplinary assumptions (Garrow and Shove, 2007). Much of this work, however, has minimally situated interdisciplinary interactions within fields that have negotiated and evolving boundaries, not only possibilities and opportunities.

This stems in part from prevalent narratives that frame the possibilities of interdisciplinarity in relation to the closure of disciplines. In order to understand interdisciplinarity, Abbott suggests, one must delve into the Chaos of Disciplines because 'interdisciplinarity presupposes disciplines' (2001, p. 135). Tracing the development of social scientific disciplines, Abbott suggests that they are not only crucial for organizing university structures and labour markets, but also for reproducing and bounding epistemologies - disciplines 'create modes of knowledge that seem, to the participants, uniquely real' and 'define what it is permissible not to know' (2001, p. 130). Similarly, Barry et al. note how 'disciplines discipline disciples': 'ensuring that certain disciplinary methods and concepts are used rigorously and that undisciplined and undisciplinary objects, methods and concepts are ruled out' (2008, pp. 20-21). Interdisciplinarity has conversely been positioned as creating space for 'boundary transgressions' and movement beyond 'existing knowledge corpuses' (Barry et al., 2008, p. 21). Drawing on Dogan and Pahre's work (1990), Urry suggests that 'innovation results from academic mobility across disciplinary borders, 
a mobility that generates what they call 'creative marginality' (2000, p. 210). The diversity of assumptions, precedents, frames, and approaches informing interdisciplinary engagement support creative interactions with varied audiences, methods, empirical sites, or theoretical precepts. The promise of such interdisciplinary engagement between migration and mobilities researchers has been long noted (Blunt, 2007; Hannam et al., 2006; King, 2012).

The potential for creativity and collaboration, however, is only one dynamic, and as Barry et al. show, emphasizing the innovation of interdisciplinarity can hide the varied logics and exchanges at work (2008). As Bourdieu suggests (1984), fields are united by common values and stakes, but also remain sites of struggle. The epistemological commitment of both migration and mobilities research to studying systems of global movements necessitates dialogue between researchers from anthropology, cultural studies, geography, history, sociology and other areas. Yet in part thanks to this dialogue, each field is internally divided - with researchers using varied approaches to study related topics (Adey et al., 2014) and diverse empirical cases obstructing the creation of shared theories (Castles, 2010, p. 1566; King, 2012, p. 138). The internal complexity of interdisciplinary fields is glossed over in critiques that acknowledge only early publications (Kalir, 2013) or oversimplified 'founding premises' (Franquesa, 2011): these fail to recognize that any consensus is a negotiated, relational, and partial accomplishment. Moreover, while some scholars engage across (inter)disciplinary borders, others do not. The potential for mobilities researchers to engage with those studying migration, tourism, transport, communication or socio-technical systems has been taken up, but incompletely and with varied impacts upon these established fields of study. All of these dynamics suggest that there is much more to interdisciplinary fields than is often addressed in summary assessments or compressed histories.

Taking up questions of temporality thus provides a way of looking more closely at how the boundaries of these interdisciplinary fields - migration and mobilities research - have changed, and with what consequences for exchanges and dialogue between them. While Abbott notes that the relationship between interdisciplinarity and disciplines is longstanding, his assumption that they coexist as complementary forces of intellectual development (e.g. , 2001, p. 150) obstructs recognition of how interdisciplinary fields change over and in relation to time. For Abbott, interdisciplinary interactions are problem-driven, and thus have limited life cycles (2001, p. 134). Yet both migration and mobilities research have examined multiple problems, and neither appears to be losing momentum due to a waning of interest. Indeed, at times they better fit a model of 'academically oriented interdisciplinary research' that seeks to answer new questions than a 'problem focused' one where the emphasis is upon social or policy relevance (Lyall et al., 2011: ch 2). Temporal dynamics within the fields, particularly in terms of how concepts are engaged with over and in relation to time, therefore call for additional attention.

This paper is structured around examinations of the temporalities of circulating concepts - a/synchronous interests in similar concepts; the sequencing of concepts, concerns and audiences; and the accumulation of limited understandings of the 
social world over longer periods of time. By tracing the movement of concepts that reach limited audiences, receive limited approval and frame limited understandings of the world, the paper highlights the contingency and complexity of interdisciplinary fields, and argues that they can, like disciplines, 'define what it is permissible not to know' (Abbott, 2001, p. 130) and rule out un(inter)disciplinary concepts. Mobilities and migration scholars have not equally embraced the concepts discussed in this paper, and addressing their circulation is a part of both recognizing the limits of potential interdisciplinarity and situating past and future contributions.

In addition, the discussion highlights how attending to the circulation of concepts can be important for reflexive assessments of research. As Bourdieu notes, the logic of the analyst differs from the practices of those she studies (1990). Reflecting upon the temporalities of conceptual categories and circulations is therefore important for acknowledging and responding to the distortion analysts impose upon understandings of the social world. While interdisciplinary fields may start off as spaces in which to engage with concepts and cases not legitimated by other disciplines, over time they too can develop assumptions and boundaries that require critical reflection.

The paper takes up these themes by addressing the circulation of several different concepts. It first discusses how concepts of transnationalism and mobility have circulated, and with what implications for temporalities of interdisciplinary interaction. It then discusses pairs of concepts that seek to counter each other's limits. After reviewing how 'methodological nationalism' points out the limitations of normalizing and privileging 'nations', it introduces the new concept of 'migrant exceptionalism' to highlight similar limitations with the normalizing and privileging of 'migrants'. Throughout, the temporalities of conceptual mobilities are used to highlight how interdisciplinary fields are shaped by limits and boundaries as much as boundary crossing.

\section{Asynchronous engagement with transnationalism}

The circulation of ideas upon which research depends, and to which it contributes, is reliant upon particular moments of synchronization. Schedules must be synchronized so that ideas can flow between people during meetings or interviews. The synchronization of research outputs with policy or news cycles is important for finding a wider audience and encouraging the circulation of findings. Within interdisciplinary dialogues, the temporal alignment of interests matters as well. That is, taking the contingency of social life seriously requires an acknowledgment that interdisciplinary dialogues are never inevitable and that the circulation of ideas between fields can face obstacles related to their temporality. To highlight this point, I turn to a particular concept - transnationalism - and consider how the temporality of its circulation within migration studies was important for subsequent engagement with mobilities research. 
Since the 1990s, transnationalism has been 'arguably the dominant paradigm in migration studies' (King and Christou, 2011, p. 454). Though the term 'transnational' began to appear several years earlier, the first major attempt to specify it as a conceptual and analytic framework came from Basch et al. (1994). They define transnationalism as:

the processes by which immigrants forge and sustain multi-stranded social relations that link together their societies of origin and settlement. We call these processes transnationalism to emphasize that many immigrants today build social fields that cross geographic, cultural and political borders. (Basch et al., 1994, p. 7)

Though this definition was novel, the practices it highlights were not. Finding a concept to bring them together, however, was important because despite the precedents for these practices:

what was lacking was a cogent theoretical perspective to illuminate their similarities so that they could be identified as in some sense 'the same'. Absent this perspective, such instances would remain isolated historical tales without cumulating, in any sense, toward the development of new typologies or predictions. (Portes, 2003, p. 875)

Basch et al. therefore drew conceptually upon discussions of migration, nations, world systems and race to outline several theoretical premises underlying studies of the transnational (1994: Ch 2). While discussions initially focused on the transnational practices of elites and migrants from the developing-world, calls for explorations of " "middling" forms of transnationalism' have subsequently examined experiences such as gap years and study abroad visits (Conradson and Latham, 2005, p. 229). Within migration research, discussions of transnationalism questioned the naturalization of nation-states as contexts for studying social phenomena, as well as the set of concepts that presume or reinforce this frame.

This questioning of nation-states, and of assumptions that societies are rooted within their boundaries, has also been a concern within mobilities research (e.g. Urry, 2000). Yet this interest was not synchronized with engagement around transnationalism. The transnational turn started several years earlier, with discussions of migration scholars 'turning transnational' (Bailey, 2001) and a 2003 special issue highlighting the 'growing acceptance of a transnational perspective among migration scholars' (Levitt et al., p. 565). Only after the heralding of the 'new mobilities paradigm' (Sheller and Urry, 2006) and introduction of the journal Mobilities in $\mathbf{2 0 0 6}$ did similar discussion occur as a part of an explicit mobilities turn.

The temporalities of these discussions - of transnationalism on one hand and morethan-national mobilities on the other - is important for understanding the somewhat muted enthusiasm for mobilities research amongst migration scholars. Despite explicit recognition that 'migration studies are crucial to the field of mobilities research' (Hannam et al., 2006, p. 10), the last decade has suggested that engaging with the mobilities turn is not similarly 'crucial' for migration scholars. King notes this ambivalence: "on the whole, geographers seem not to have "bought into" the mobilities paradigm in the same way that they have carried out research on migrant transnationalism' (2012, p. 143). Though the reason for this remains 'something of a 
mystery' for King (2012, p. 143), I argue that it in part relates to asynchronous interest in similar concerns. Encountering discussions of transnationalism and mobilities in sequence, rather than simultaneously, could lead the latter to appear as 'more of the same', despite its different ontological positioning (elaborated in the next section). In an academic culture where new contributions are prized and marking one's work as distinctive is crucial, there is little reason to spend time on repetitive conversations. One of the reasons migration research was deemed crucial to mobilities work was that its discussions of transnationalism were extremely pertinent for studying a world of global mobilities. Yet the sequencing of this influence also meant that initial discussions of mobilities were not entirely novel to migration researchers.

What this highlights is that both the timing and direction in which ideas flow matter for how interdisciplinary engagements emerge. While mobilities and migration research have shared concerns about how social relations span societies, and how border crossings and global travel fuel transnational connections, their asynchronous engagement with these concerns limited the extent to which they have been examined as a part of mutually engaged interdisciplinary dialogues.

\section{Sequencing concerns about mobility}

As the previous section highlighted, the asynchronous circulation of ideas between interdisciplinary communities has consequences for dialogues due to how the sequencing of ideas affects assessments of their contributions. Though in this case the result was largely ambivalence, in other cases the sequencing of ideas can lead to open contestation. This corresponds with different understandings of sequencing as a) subsequent, emergent intervals in time or b) strategic ordering and prioritization. In the former, concepts can be seen to have relationships of temporal succession, particularly over longer periods such as years or decades, but these are not taken to be indicative of their relative importance, since longstanding concepts can remain incredibly pertinent. When the focus moves to how authors prioritize concepts within an existing vocabulary, however, one concept coming before another can be an indicator of strategic importance and the politics of ordering. To expand upon the latter, I consider understandings of 'mobility' and 'migration' in each of these fields.

Looking at understandings of 'mobility' within migration and mobilities research highlights important ontological differences. Within journals such as the International Migration Review or the Journal of Ethnic and Migration Studies, there is discussion of 'social mobility' between classes and economic brackets, or 'spatial mobility,' such as migrants' inter-city movements. In these cases, the concept remains predominantly focused on people (i.e. migrants), with a particular concern for the link between spatial displacement and changes in social position (e.g. Faist, 2013). Mobility is a quality of a person, and can occur in relation to objective space or social hierarchy. 
Mobilities research, however, emphasizes that multiple mobilities are entangled in social processes and structures, including 'the large-scale movements of people, objects, capital and information across the world, as well as the more local processes of daily transportation, movement through public space and the travel of material things within everyday life' (Hannam et al., 2006, p. 1). This marks a clear difference in ontological focus - mobilities research considers multiple interrelated actors human (backpackers, car drivers, enthusiasts) and non-human (backpacks, cars, binoculars) (Dant, 2004; Hui, 2012; Walsh and Tucker, 2009). The emphasis upon the movement of things other than humans has been noted as one of the field's contributions to social research (Cresswell, 2011, p. 552) and is important for its aim of countering sedentarist accounts that normalize or privilege stasis (Sheller and Urry, 2006; Urry, 2007). Paying attention to both humans and objects as a part of larger systems of mobility is key for Urry because assemblages of mobilities both 'contingently maintain social connections' across space $(2007$, p. 48$)$ and point to 'the significance of systems that distribute people, activities and objects in and through time-space' (2007, p. 51). Though not all research within the mobilities turn embraces non-human actors, or discussions of assemblages, the plurality of types of mobilities and units of study is an important part of the field's strategic diversity. By comparison, although migration research incorporates what mobilities scholars would see as different mobilities - of monetary or object remittances, of communications, of ideas and imaginings - these are not often treated as units or actors of equal importance.

For mobilities researchers then, both an interest in (non)human actors and the acknowledgment of multiple mobilities leads to seeing migration as one of multiple phenomena, and one of multiple literatures that contribute to understandings of mobilities. That is, mobility is prioritized as a concept, of which migration is one subtype.

Yet within migration studies, the categories of 'migration' and 'mobility' do not necessarily overlap, let alone have this ordering. Faist suggests that in both public debates and academic research, it is increasingly labor migrants, not necessarily welcomed by nation-states, who are seen to 'migrate', while highly skilled professionals are not immigrants but 'mobiles' (2013, p. 1642). Castles notes the same discursive phenomenon, where 'mobility equaled good, because it was the badge of a modern open society; migration equaled bad because it re-awakened archaic memories of invasion and displacement' (2010, p. 1567). This 'glamorization' of mobile people in public discourse is seen to be problematic, and a reason to question discussions of 'mobile' people within academic circles (Glick Schiller and Salazar, 2013, p. 184).

This concern for the entanglement of public and academic discourses suggests that it is not only the ordering of particular concepts that is at stake - it is also the ordering of audiences. While a concern for public discourse exists in many areas of academic research, migration studies have been strongly engaged in policy-related research due to government concerns about the politicization of immigration (Castles, 2010, pp. 1570-1571). In addition, policy-driven consulting has often been a key source of 
funding for migration research centers (Castles, 2010, p. 1572). For some migration researchers then, the importance of engaging with non-academic audiences means that this differentiation between migration and mobility is one that they must reproduce or to which they must respond. That is, when engaging with nonacademic audiences comes first, appropriate vocabularies are negotiated in response.

Another aspect of the debate over 'migration' vs. 'mobility', however, is that prioritizing the latter has been seen as problematic for considerations of social inequality and power. When researchers first engaged in discussions of transnationalism, some critiques focused on its tendency 'to overemphasise the hyper mobility of an elite few' (Collins, 2009, p. 4). Warnings that 'sampling on the dependent variable' could hide the absence of transnationalism therefore led to convergence around the understanding that 'not all immigrants are transnationals' (Portes, 2003, p. 876). In this context, the suggestion that all migrants can be discussed in terms of mobility is contentious because of concerns that this deemphasizes or erases the inequalities of global migration (Faist, 2013; Glick Schiller and Salazar, 2013). In an early critique of mobility research, Skeggs suggests that identifying mobility in 'a horizontal rather than a vertical sense' ends up 'flattening out the differences that have to be crossed' and thus obscuring class, power, and the problematic influence of individualism (2004, p. 48). Even though dimensions of inequality have been addressed within the mobilities turn (Ohnmacht et al., 2009), and mobilities research creates space to consider intersectional and systemic aspects of inequality or privilege, for some scholars inequalities and power relations should be more central, and require more specific framings of mobility (e.g. Glick Schiller and Salazar, 2013). The politics of what might be lost in prioritizing a general frame of mobilities have thus remained a point of tension between fields.

As this shows, discussions about the concept of 'mobility' and how it relates to 'migration' are intricately connected to political concerns and the contexts of academic practice. The sequence in which concepts are placed can be taken as an indication of the prioritization of particular audiences, actors, or politics - whether such ordering was intended or not. Occasional misunderstandings have occurred between these fields - with an interest in 'mobilities' being misread as a lack of interest in inequalities.

What this example further highlights is that for some groups within migration studies, there are impermissible sequences for concepts. That is, some boundaries are not appropriate to cross and some distinctions must not be blurred. As a result, interdisciplinary dialogue with mobilities researchers becomes inappropriate. While some migration researchers have engaged with 'mobility', for others the possibility of doing so has reinforced differences and sparked attempts to regulate what should (not) be known.

What is important, however, is not just the relative positioning attributed to migration and mobility, but the extent to which each concept bounds possible understandings of the social world. Abbott's discussion (2001) highlights how even 
disciplines are marked by fractal differentiations that re-work relationships between concepts over time. It therefore becomes important to consider how continued attention to particular concepts can, eventually, accumulate a range of effects with particular limitations and implications for further dialogue.

\section{The long-term consequences of engaging with limited concepts}

The sequence in which concepts are encountered, or placed, has been highlighted as important for the contingent emergence of interdisciplinary encounters, and enduring frictions within them. But as Abbott (2001) highlights, sequences of interactions also have important consequences for understanding the development of social scientific knowledge over time. He compares the accumulation of understandings about the social world with exploring the streets of a city, suggesting that the particular process through which groups split up and turn down different streets, to explore new territory and learn new things, compounds with implications for how much of the city can be discovered. Over longer periods of time, the paths of many pedestrians can create patterns of investigation that 'systematically ignore places' (2001, p. 31). That is, depending on the extent to which explorations are concentrated in a particular area, more or less of the city becomes known. While Abbott uses this example to discuss the development of disciplines and subdisciplines, I argue that it is also relevant for thinking about how knowledge accumulates within interdisciplinary communities. If interdisciplinary exchanges are not always problem-focused, but are also shaped by shared and contested concepts, then how these affect social explorations is important.

This section therefore looks at two pairs of concepts wherein the circulation of one is initiated to counter the limited paths of exploration enforced by the other. The dynamics between such concepts are important because they seek to destabilize biases that can accumulate over time in relation to what it is permissible to know and not know. They also suggest that there is a danger even within interdisciplinary fields for the entrenchment of core concepts to produce significant gaps in understandings of the social world. To begin outlining these dynamics, we first turn to the pairing of 'nations' and 'methodological nationalism'.

\section{Nations and methodological nationalism}

As discussed above, the concept of 'nation' has been challenged in discussions of both transnationalism and mobilities. Urry has questioned the longstanding assumption that nations are natural 'containers' for society, highlighting that social transformations necessitate a re-thinking of the role of nations (2000). Wimmer and Glick Schiller have similarly critiqued what they call 'methodological nationalism' 'the assumption that the nation/state/society is the natural social and political form of the modern world' (2002, p. 302). In their analysis, the continuing relevance and persistence of nations as a central frame is tied to academic practices and research processes. National political agendas and research funding, for instance, encourage and constrain researchers - supporting studies that focus on the nation-state while 
making projects based in other countries or spanning across borders more difficult. Wimmer and Glick Schiller acknowledge that there are discontinuities and changing national stances towards immigration, but argue that methodological nationalism has become a pervasive characteristic of migration research. In this context: the value of studying transnational communities and migration is not to discover 'something new' - though this represents a highly rewarding strategy of research in our contemporary intellectual environment - but to have contributed to this shift of perspective away from methodological nationalism. (Wimmer and Glick Schiller, 2002, p. 302)

By introducing the concept of 'methodological nationalism', Wimmer and Glick Schiller, whose argument is worth reading in its entirety, point out the limits in knowledge accumulated through a continued focus upon nations. The concept brings attention to how deeply embedded assumptions about the importance of nations systematically ignore some aspects of social life, including transnational processes and experiences.

Challenging the relevance of nations and nationalism is not about denying that they have influence. It is about questioning whether they are always relevant as a primary frame for studying the social world. As Wimmer and Glick Schiller note, 'every clear conceptual structure necessarily limits the range of possible interpretations, as well as the empirical domains that can be meaningfully interpreted' $(2002, p$. 326). The concept of methodological nationalism, and its call to recognize the discontinuous and intermittent relevance of nations, thus acknowledges that multiple interpretations are important for making sense of global societies. By reflexively framing the biases of previous research, it points to the importance of studying areas that have been previously ignored.

\section{Migrant and migrant exceptionalism}

Within migration studies, the concept of 'methodological nationalism' has circulated widely, contributing in part to the establishment of transnationalism as a popular frame for contemporary research. When considering the interdisciplinary exchanges between migration and mobilities scholars, however, it becomes clear that 'nation' is not the only concept that limits understandings of social life. 'Migrant' is similarly problematic. Bailey suggests that transnational frameworks for research are marked by a suspicion of how 'migrant types are defined and classified', particularly in relation to nation-states, and of 'the conceptual and political usefulness of the migrant types that are produced by the above classification' (2001, p. 415). A mobilities framework, however, does not stop here. It is also suspicious of how types of mobile people (and flows more generally) are defined and classified. 'Migrants' do not exist a priori, but are linked to nations and countries that 'make' migrants through regulations, visas and border processes. Moreover, 'migrant' is but one of a diverse array of subject-positions relevant for studying mobilities, including tourists, soldiers, drivers, loiterers and the impaired (Adey et al., 2014). The importance or atemporal relevance of 'migrants' cannot be assumed, as it may not be conceptually or politically useful for understanding the complexities of social phenomena. 
I therefore argue that the concept of 'migrant' needs to be paired with an understanding of 'migrant exceptionalism' - the assumption that migrants are extraordinary mobile subjects, discrete from other (concurrent) subject positions, and central units within methodologies. Though focusing on migrants may be important for specific empirical studies, the accumulated effects of this focus have limits and create absurdities. Halfacree, for instance, suggests that many studies of migration have, despite an attention to movement, privileged settlement in place: since 'any migration is likely to be "temporary" in terms of the duration of a person's life, the very idea of "permanent" migration increasingly seems a product of an implicit assumption of normative sedentarist settlement' (2012, p. 213). Nonetheless, the dominance of methodological nationalism in post-war research reinforced categories of permanent and temporary migrants, which privileged the isolated moments of border crossing (Meeus, 2012, p. 1777). Subsequently, the temporal frame for migration research has broadened to consider transnationalism and how 'the process of migration does not stop after physical movement to another country' (Meeus, 2012, p. 1779). But if migration does not stop after moving to another country, when does it stop? Or more precisely, when do 'migrant' practices give way to other types of practices, making migration no longer of primary relevance when orienting research?

Too often, this question is given little attention. In part, this is due to the professional institutions, journals, policy frameworks, and academic conferences that foreground migration and migrants. Whether the name of a migration research center, the framing of policies around migrant issues, or conventions of style and terminology in particular journals, the embedding of migrant exceptionalism at multiple levels, in multiple organizations, makes questioning its operation politically sensitive and combatting its prominence a significant challenge. Migrant exceptionalism is no less embedded in social institutions than methodological nationalism. Indeed, it is an offshoot of methodological nationalism, as it depends upon the privileging of a status regulated and enacted by nations. Naming migrant exceptionalism is therefore important for recognizing the consequences and limitations of this assumption, and ensuring that important social dynamics are not being obscured through its reproduction.

Just as with nations, challenging the relevance of migrants is not about denying their existence or importance. It is about questioning the extent to which they are normal or appropriate subjects for research. As Halfacree highlights, in certain contexts and for specific social or political reasons it is crucial to maintain distinctions between migration and other phenomena (2012). But before and after migration events, migrants are people - with complex practices and roles. Recognizing this requires not taking the appropriateness of 'migrant' for granted. It is not that 'migrants' needs to be replaced with 'mobiles', but that work is needed to look beyond inherently limited assumptions about 'migrants'.

Though it might appear that migrant exceptionalism is only a problem for migration researchers, this is not the case. Naming and circulating this concept is also important for mobilities researchers. After all, while there is a recognition of the 
multiple subject positions that (im)mobile people take up, and of the multiple structures that enact such positions, empirical studies have too often focused on only one position or sphere of activity. Studies of cyclists and of air travellers have too rarely considered how one person is often both, at different times. Likewise, literature on migrants and migrant experiences is too seldom cited in discussions of other mobilities. The seemingly normal separation of discussions of cycling, flying, and migrating is thus an indicator that even within mobilities research migrants (and other types of mobile subjects) can be treated as exceptional. It is therefore not enough to suggest as Collins does that 'non-migrants' and 'migrants' should be studied in relation to each other, and with a concern for relational mobility and immobility $(2009$, p. 18; 2011). This still privileges and reproduces categories that are framed from the position of nation-states. Within individuals' biographies, 'nonmigrant' and 'migrant' roles may be interwoven in surprising ways, or even be largely irrelevant to the practices of everyday life. At the same time that some migrants live in a state of 'permanent temporariness' whereby migration status is a continual obstacle in everyday life (Bailey et al., 2002; Collins, 2011), others go through periods when having migrated is of limited relevance. The multiple roles and experiences of diverse and unequally privileged people therefore provide a more appropriate starting point.

While at times migration may seem irrelevant for studying other mobilities, there is much to be gained from further interdisciplinary exchange. Passports, for instance, facilitate entry through physical border crossings, but also act as proof of identity to facilitate access to and communication with financial and bureaucratic institutions. The intertwined practices and politics of migration, finance and digital communication systems could therefore be investigated in more detail. Reflecting upon the limits of migrant exceptionalism could also encourage further consideration of the temporalities of experience at stake in studies of mobilities. Within migration research, maintaining a focus upon migrants has provided vivid understandings of the longer-term effects of migration processes upon people's lives - temporalities that have been given limited attention within studies of mobilities. ${ }^{\text {i }}$ The sequencing of a migration event before other experiences has been shown to affect interactions and mobilities even years later. Useful insights could therefore arise from extending the implications of this approach to people's multiple, sequenced careers as car drivers, migrants, cyclists, and smart phone users. In addition, the longer-term consequences of migration events suggest the importance of developing mobile methods (Büscher and Urry, 2009) that attend to processes and data over longer time periods.

The concept of migrant exceptionalism thus has the potential to encourage new interdisciplinary exchanges because it points to the limitations of how both migration and mobilities researchers have addressed the category of 'migrants'. It does not suggest that migrants must be subordinated to other categories of mobile subjects, but encourages reflection upon their normalization as an exceptional group. In order to counter the limits of migrant exceptionalism, further engagement with cases that embrace multiple subject positions and mobilities systems, with 
temporally fluctuating prominence, will be important. The next section illustrates two such cases that devote attention to sometimes-migrants.

\section{Exploring cases of sometimes-migrants}

The first case involves the complexity of pregnant mothers from China who travel to Hong Kong in order to give birth. Since 2001, Hong Kong has seen a considerable increase in the number of Mainland Chinese women who travel there on temporary visas in order to give birth. While in 2001 only 1.3\% of the city's live births were to parents who did not have HK permanent residency, by 2011 this figure had grown to $37.4 \%$ of the over 95,000 births (Lam and Chan, 2013). .i The surge of birth tourism, which has been supported by niche businesses that aid mothers with entry and find them places to live before their 'emergency' births in the city, was facilitated by two significant events. First, in 2001, a court decision granted Hong Kong Permanent Residency to children born in the city, regardless of the residency of their parents. Then in 2003 the introduction of the Individual Visit Scheme to boost tourism after the SARS outbreak made it possible for Mainland residents to visit Hong Kong without an official tour group (Tsoi, 2012). After these developments, birth tourism became an option for both parents hoping to evade China's 'one child policy' and those attracted by the benefits of Hong Kong citizenship, including education and health care provisions (Basten and Verropoulou, 2013, p. 332). After birth, families return to other parts of China. But many leave the city with the anticipation that their child will return - both to apply for documents such as the Hong Kong ID cardiii, and for health care or education. Such return mobilities have begun to materialize, particularly in the shape of children who are commuting across the Hong Kong-China border every day in order to attend school (Yuen, 2011). As Li's research shows, even those families who do not send their HK-born children to the city for early education still anticipate that they may later go there for secondary or post-secondary study (2013).

This case features a complex interweaving of tourism, migration and everyday travel at multiple scales. The phenomenon of 'birth tourism' was an unintended consequence of a legal judgment and a tourism policy in Hong Kong, and subsequent attempts to stop it have focused on restricting practices within both the health and immigration sectors (Cheng, 2007; Deng, 2012). Thinking more specifically about the experiences of families, it is clear that birth tourism sets up a complex series of mobilities. Yet these do not fit neatly within understandings of chain migration, whereby family members follow each other on migration journeys (MacDonald and MacDonald, 1964). Instead, a mother's 'tourism' leads to a child's 'migration'. Thereafter, family travel can become a confusing juxtaposition of both 'tourism' and 'return visits' for the citizen-child. In some cases, children are not quite 'student migrants' but more like 'educational return migrants', with 'migrations' every day, week, or school term. The richness of this case is apparent, and yet studying it within a framework of 'tourism' or 'migration' would put selective emphasis upon what is a broader set of mobilities with diverse structural and personal implications. 
The second example draws upon my work examining the role of materialities within the lives of return migrants (Hui, 2015). While several excellent studies have discussed the importance of objects to the constitution of migrant homes and journeys (Burrell, 2008, 2011; Nowicka, 2007; Tolia-Kelly, 2004; Walsh, 2006), my project broadened the temporal scope to investigate how mobile things and people are intertwined over the course of return migration. In addition to two semistructured interviews addressing objects that were taken and used during different migration episodes, Hong Kong-based participants completed 'object experiment books' that were inspired by the diverse creative exercises in 'probes' (Boehner et al., 2012). These books asked participants to 'follow' one object that was important in their everyday lives, discussing its mobilities past and present in both documentary and creative ways.

Methodologically, these exercises could be seen to take a significant risk. Since participants had diverse migration experiences - with some first leaving Hong Kong in the 1970s and others in the 2000s - as well as different numbers of return cycles, the time since their most recent migration varied widely. To what extent would contemporary object mobilities be relevant for an understanding of their migration? Or in what times and contexts would the mobilities of objects shed light on migration per se as opposed to other dynamics of social life? Collecting and packing things to be shipped to another country clearly links object mobilities with migration. Experiences of living abroad are also materialized when return migrants like Daniel and Jason redecorated their kitchens using appliances that were standard in previous homes but unusual in their current city. But at other times objects have more ambiguous roles. An iPhone is a means of connecting with a daughter who has re-migrated to a country of previous residence for education, but it can also be a mobile radio that is no different in the hands of a return migrant than any other person. At those moments, it seems inconsequential that the person you are speaking to is a return migrant. By pursing an interest in both mobile people and mobile objects, this project took the risk that some of its insights might not be about migration at all. Objects are not migrants or tourists or non-migrants, though they may be moved between countries, taken on vacation and used in unremarkable parts of everyday life. Recognizing this prompts considerations of how people are also articulating between different roles, communities, and institutions of relevance.

As these cases illustrate, moving beyond migrant exceptionalism is important because in the context of people's whole lives, migration is not the only frame that helps to make sense of change, adaptation, social roles, power or inequality. Neither are the social systems and diverse mobilities that affect these processes solely oriented towards 'migration'. Tourism, health and education policies can have complex implications for the regulation of migration. Expanding attention to recognize both migration and dynamics that are entangled, but beyond the realm of what is labelled migration, is therefore the important impetus for recognizing and countering migrant exceptionalism.

Some indications exist that support for moving beyond migrant exceptionalism is already building. Castles has suggested the potential of re-situating theories of 
migration within studies of social transformation: 'A key aspect of this conceptual framework would be that it should not restrict itself to migration, but rather seek to link analysis of migratory processes to broader social theory and through this to the analysis of societal change in general' (2010, pp. 1582-1583). Rogers is similarly concerned about the limits of 'migration', and points to how migrants are not the only groups involved in transnational interactions (2005). He therefore suggests the possibility of 'folding transnationalism into a generalised study of mobilities and immobilities, in line with John Urry's "sociology beyond societies" (Urry 2000)' (Rogers, 2005, p. 404). Any movement into such interdisciplinary spaces, however, will require careful attention to existing ontological and political differences. Favell, for example, echoes the above calls to re-situate migration studies, but suggests that migration should only become 'a subset of (spatial) mobility studies' if it can retain a focus 'on real people moving in real space-not virtual and nonhuman forms of mobility' (2007, pp. 271-272). For Favell, the sequencing of agents is not negotiable, and people must remain ontologically primary. This is not necessarily an obstacle to interactions with mobilities research, as not all work within this field takes up nonhuman or virtual mobilities. Yet it may also prompt new debates about the sequencing of concepts and concerns to on one hand counter the effects of migrant exceptionalism and on the other hand maintain particular hierarchies of ontological status.

Regardless, there is space for further interdisciplinary engagements to grow out of attempts to counter the limitations of migrant exceptionalism. While it is possible that a lack of synchronicity or contested sequences of concepts will yet again become obstacles to further dialogue, it is also possible that this is the right time for collaborations that extend the already impressive work emerging between these fields. Engaging collaboratively around cases of sometimes-migrants could be incredibly fruitful. Whether it sparks such contributions or not, resisting migrant exceptionalism is important in order to attend to aspects of social life that have been permissible not to explore.

\section{Conclusion}

While interdisciplinary fields provide fruitful opportunities for invention and exploration, this paper has shown that their histories include much more. At the same time that engaging with shared problems or concepts can generate new contributions, it also leads to silences, struggles and attempts to limit the momentum of particular trajectories of development. Imaginings of interdisciplinary fields as open spaces for boundary crossing are therefore incomplete. Not only do these fields have various boundaries that help to define them, but they also involve attempts to define what it is permissible not to know. The possibility of interdisciplinary interactions can spark both collaboration and attempts to rule out un(inter)disciplinary concepts. A discussion of such instances has been facilitated through close attention to the circulation of concepts that are ignored, contested, or inherently limited. 
While one potential future trajectory is for these interdisciplinary fields to become increasingly 'disciplinary' in the management of acceptable knowledge and concepts, the paper highlighted how there is also considerable space for boundaries to change and for limitations to be challenged. Boundaries emerge within longstanding interdisciplinary fields, but they also become contested through the circulation of new concepts that highlight long-term consequences of latent assumptions. Introducing the concept of migrant exceptionalism highlights the need to reflect upon and contest assumptions about the atemporal relevance and extraordinary position of 'migrants'. Though assuming the ongoing relevance of migrants is easily done, questioning the limits of this concept is an important part of recognizing the distinction between academic practice and social life. Research traditions may perpetuate attention to certain concepts, but this does not mean that they remain the most useful ones for understanding the social world. Acknowledging migrant exceptionalism is therefore important for situating the limited relevance of 'migrants' and creating space to consider sometimes-migrants and the multiple systems their mobilities are shaped by.

This paper has also made important contributions to understandings of how temporalities are constitutive, and not only characteristic, of interdisciplinary exchanges. While cursory characterizations of interdisciplinary interactions are rhetorically convenient, they can imply that shared concerns, common concepts or ongoing dialogues are atemporal and inevitable, rather than negotiated, emergent and contingent. This discussion therefore points to the need for temporally-situated and temporally-sensitive accounts of interdisciplinary fields: accounts which are sensitive to a/synchronous flows of and engagement with ideas, to what is at stake in the ordering of concepts, and to the accumulated limitations of even dominant frames.

Finally, this paper has added to characterizations of the intertwined histories of migration studies and mobilities research. While there has already been a significant body of collaboration between researchers in these fields, boundaries and obstacles have at times limited engagement. The discussion made clear that shared ideas are not always enough to prompt mutually beneficial dialogues. Finding new questions or problems that engage researchers from both fields will therefore be crucial for future interdisciplinary engagement between them. This paper has suggested that shared attempts to counter migrant exceptionalism and study sometimes-migrants within interlinked social systems could be one such project, which could contribute new interdisciplinary understandings of our complex, changing social worlds.

\section{Acknowledgments}

The author would like to thank James Faulconbridge, Jen Southern, Kathy Burrell, and the reviewers for helpful comments on previous versions of this paper. An early draft was presented at the Global Mobility Futures conference at Lancaster University, 6 September 2013.

\section{Notes}




\footnotetext{
'Many thanks to Kathy Burrell for bringing this point to my attention.

ii While these figures include the children of Hong Kong residents with short-term work visas, a substantial proportion of the growth is from visitors with temporary tourist visas.

iii Children over the age of 11 can apply for this card, which has a chip including biometric information and allows access to public services as well as fast-track passage through immigration checkpoints.
}

\section{Bibliography}

Abbott, A. (2001) Chaos of disciplines (Chicago: University of Chicago Press). Adey, P., et al. (Eds.) (2014) The Routledge handbook of mobilities (London: Routledge).

Ahmed, S., et al. (Eds.) (2003) Uprootings/regroundings: questions of home and migration (Oxford: Berg).

Bailey, A.J. (2001) Turning transnational: notes on the theorisation of international migration, International Journal of Population Geography 7, pp. 413-428.

Bailey, A.J., et al. (2002) (Re)producing Salvadoran transnational geographies, Annals of the Association of American Geographers 92 (1), pp. 125-144.

Barry, A., Born, G., and Weszkalnys, G. (2008) Logics of interdisciplinarity, Economy and Society 37 (1), pp. 20-49.

Basch, L., Glick Schiller, N., and Szanton Blanc, C. (1994) Nations unbound: transnational projects, postcolonial predicaments, and deterritorialized nation-states (Amsterdam: Gordon and Breach).

Basten, S. and Verropoulou, G. (2013) 'Maternity migration' and the increased sex ration at birth in Hong Kong SAR, Population Studies 67 (3), pp. 323-334.

Blunt, A. (2007) Cultural geographies of migration: mobility, transnationality and diaspora, Progress in Human Geography 31 (5), pp. 684-694.

Boehner, K., Gaver, W., and Boucher, A. (2012) Probes, in C. Lury and N. Wakeford (Eds.) Inventive methods: the happening of the social, pp. 185-201 (London: Routledge).

Boix Mansilla, V., Dillon, D., and Middlebrooks, K. (2002), Building bridges across disciplines: organizational and individual qualities of exemplary interdisciplinary work, (Cambridge, Mass.: Good Work Project; Project Zero: Harvard Graduate School of Education), 73.

Bourdieu, P. (1984) Distinction: a social critique of the judgement of taste, trans. R. Nice (London: Routledge).

--- (1990) The logic of practice, trans. R. Nice (Stanford: Stanford University Press).

Burrell, K. (2008) Materialising the border: spaces of mobility and material culture in migration from post-socialist Poland, Mobilities 3 (3), pp. 353-373.

--- (2011) Going steerage on Ryanair: cultures of migrant air travel between Poland and the UK, Journal of Transport Geography 19, pp. 1023-1030.

Büscher, M. and Urry, J. (2009) Mobile methods and the empirical, European Journal of Social Theory 12 (1), pp. 99-116.

Castles, S. (2007) Twenty-first-century migration as a challenge to sociology, Journal of Ethnic \& Migration Studies 33 (3), pp. 351-371. 
--- (2010) Understanding global migration: a social transformation perspective, Journal of Ethnic \& Migration Studies 36 (10), pp. 1565-1586.

Cheng, M.H. (2007) Hong Kong attempts to reduce influx of pregnant Chinese, The Lancet 369 (9566), pp. 981-982.

Collins, F.L. (2009) Transnationalism unbound: detailing new subjects, registers and spatialities of cross-border lives, Geography Compass 3 (1), pp. 434-458.

--- (2011) Transnational mobilities and urban spatialities: notes from the Asia-Pacific, Progress in Human Geography 36 (3), pp. 316-335.

Conradson, D. and Latham, A. (2005) Transnational urbanism: attending to everyday practices and mobilities, Journal of Ethnic and Migration Studies 31 (2), pp. 227-233.

Conradson, D. and McKay, D. (2007) Translocal subjectivities: mobility, connection, emotion, Mobilities 2 (2), pp. 167-174.

Crang, M. and Zhang, J. (2012) Transient dwelling: trains as places of identification for the floating population of China, Social \& Cultural Geography 13 (8), pp. 895-914.

Cresswell, T. (2011) Mobilities I: catching up, Progress in Human Geography 35 (4), pp. 550-558.

Dant, T. (2004) The driver-car, Theory, Culture and Society 21 (4/5), pp. 61-79.

Deng, A. (2012), 'Loopholes in non-resident expectant mother barrier', China Daily, China Daily <http://www.chinadaily.com.cn/hkedition/201203/03/content_14745471.htm\%3E, accessed 3 September 2014.

Dogan, M. and Pahre, R. (1990) Creative marginality (Boulder, CO: Westview Press).

Faist, T. (2013) The mobility turn: a new paradigm for the social sciences?, Ethnic and Racial Studies 36 (11), pp. 1637-1646.

Favell, A. (2001) Migration, mobility and globaloney: metaphors and rhetoric in the sociology of globalization, Global Networks 1 (4), pp. 389-398.

--- (2007) Rebooting migration theory: interdisciplinarity, globality, and postdisciplinarity in migration studies, in C.B. Brettell and J. Hollifield (Eds.) Migration theory: talking across disciplines, pp. 259-278 (2nd edn.; London: Routledge).

Fortier, A.-M. (2014) Migration studies, in P. Adey, et al. (Eds.) The Routledge handbook of mobilities, pp. 64-73 (London: Routledge).

Fortier, A.-M. and Lewis, G. (2006) Migrant horizons, Mobilities 1 (3), pp. 307-311.

Franquesa, J. (2011) 'We've lost our bearings': place, tourism, and the limits of the 'mobilities turn', Antipode 43 (4), pp. 1012-1033.

Garrow, D. and Shove, E. (2007) Artefacts between disciplines. The toothbrush and the axe, Archaeological Dialogues 14 (2), pp. 117-131.

Gill, N., Caletrio, J., and Mason, V. (2011) Introduction: mobilities and forced migration, Mobilities 6 (3), pp. 301-316.

Glick Schiller, N. and Salazar, N.B. (2013) Regimes of mobility across the globe, Journal of Ethnic \& Migration Studies 39 (2), pp. 183-200.

Halfacree, K. (2012) Heterolocal identities? Counter-urbanisation, second homes, and rural consumption in the era of mobilities, Population, space and place 18 , pp. 209-224.

Hannam, K., Sheller, M., and Urry, J. (2006) Mobilities, immobilities and moorings, Mobilities 1 (1), pp. 1-22. 
Holland, D. (2014) Integrating knowledge through interdisciplinary research: problems of theory and practice (Abingdon: Routledge).

Hui, A. (2012) Things in motion, things in practices: how mobile practice networks facilitate the travel and use of leisure objects, Journal of Consumer Culture 12 (2), pp. 195-215.

--- (2015) Networks of home, travel and use during Hong Kong return migration: thinking topologically about the spaces of human-material practices Global Networks 15 (4), pp. 536-552.

Kalir, B. (2013) Moving subjects, stagnant paradigms: can the 'mobilities paradigm' transcend methodological nationalism?, Journal of Ethnic \& Migration Studies 39 (2), pp. 311-327.

King, R. (2012) Geography and migration studies: retrospect and prospect, Population, space and place 18, pp. 134-153.

King, R. and Christou, A. (2011) Of counter-diaspora and reverse transnationalism: return mobilities to and from the ancestral homeland, Mobilities 6 (4), pp. 451-466.

Lam, J. and Chan, S. (2013), LCQ1: Mainland pregnan women giving birth in Hong Kong, in L. Council (ed.), (Press Release on news.gov.hk: Hong Kong SAR Government).

Levitt, P., DeWind, J., and Vertovec, S. (2003) International perspectives on transnational migration: an introduction, International Migration Review 37 (3), pp. 565-575.

$\mathrm{Li}, \mathrm{X}$. (2013), Connect or disconnect? Transborder activities and family networks of mainland Chinese with children born in Hong Kong, paper given at David C. Lam Institute for East-West Studies Seminar Series, Hong Kong, 25 February.

Lyall, C., et al. (2011) Interdisciplinary research journeys: practical strategies for capturing creativity (London: Bloomsbury Academic).

MacDonald, J.S. and MacDonald, L.D. (1964) Chain migration ethnic neighborhood formation and social networks, The Milbank Memorial Fund Quarterly 42 (1), pp. 82-97.

Mai, N. and King, R. (2009) Love, sexuality and migration: mapping the issue(s), Mobilities 4 (3), pp. 295-307.

Meeus, B. (2012) How to 'catch' floating populations? Research and the fixing of migration in space and time, Ethnic and Racial Studies 35 (10), pp. 1775-1793.

National Academies (U.S.), et al. (2005) Facilitating interdisciplinary research (Washington D.C.: National Academies Press).

Nowicka, M. (2007) Mobile locations: constructions of home in a group of mobile transnational professionals, Global Networks 7 (1), pp. 69-86.

Ohnmacht, T., Maksim, H., and Bergman, M.M. (2009) Mobilities and inequality (Farnham: Ashgate).

Portes, A. (2003) Theoretical convergencies and empirical evidence in the study of immigrant transnationalism, International Migration Review 37 (3), pp. 874892.

Richardson, T. (2013) Borders and mobilities: introduction to the special issue, Mobilities 8 (1), pp. 1-6. 
Rogers, A. (2005) Observations on transnational urbanism: broadening and narrowing the field, Journal of Ethnic and Migration Studies 31 (2), pp. 403407.

Sheller, M. and Urry, J. (2006) The new mobilities paradigm, Environment and Planning A 38, pp. 207-226.

Skeggs, B. (2004) Class, self, culture (London: Routledge).

Strober, M.H. (2010) Interdisciplinary conversations: challenging habits of thought (Stanford, Calif.: Stanford University Press).

Tolia-Kelly, D. (2004) Materializing post-colonial geographies: examining the textural landscapes of migration in the South Asian home, Geoforum 35, pp. 675-688.

Tsoi, G. (2012), 'Integration anxiety', HK Magazine, Fri 17 February, p. 8-14.

Urry, J. (2000) Sociology beyond societies: mobilities for the twenty-first century (London: Routledge).

--- (2007) Mobilities (Cambridge: Polity Press).

Walsh, K. (2006) British expatriate belongings: mobile homes and transnational homing, Home Cultures 3 (2), pp. 123-144.

Walsh, N. and Tucker, H. (2009) Tourism 'things': the travelling performance of the backpack, Tourist Studies 9 (3), pp. 223-239.

Wimmer, A. and Glick Schiller, N. (2002) Methodological nationalism and beyond: nation-state building, migration and the social sciences, Global Networks 2 (4), pp. 301-334.

Yuen, C.Y.-M. (2011) Towards inclusion of cross-boundary students from Mainland China in educational policies and practices in Hong Kong, Education, Citizenship and Social Justice 6 (3), pp. 251-264. 